\title{
Equivalence in Economic Translation: Challenges and Hindrances Case Study: An Economic Report on the Informal Economy in Tunisia
}

\author{
Sofiene Tergui \\ University of Humanities, Tunisia \\ Buraimi University College, Oman
}

Received: 27-08-2016

Accepted: 24-09-2016

Published: $31-10-2016$

doi:10.7575/aiac.ijclts.v.4n.4p.32

URL: http://dx.doi.org/10.7575/aiac.ijclts.v.4n.4p.32

\begin{abstract}
The notion of Translation Equivalence is undoubtedly one of the most problematic and controversial areas in the field of translation theory. The term has caused, and it seems quite probable that it will continue to cause, heated debates within the field of translation studies. Equivalence, indeed, is a constitutive feature and the guiding principle of translation. As Catford points out, "the central problem of translation-practice is that of finding Target Language equivalents. A central task of translation theory is that of defining the nature and conditions of translation equivalence" (Catford 21: 1965). In order to explore the realm of Translation Equivalence, I will try in this paper to point to the different methods used to achieve equivalence when translating an economic report entitled: Extralegality in Tunisia and the connection to the Arab Spring (2013) from English (L3) into Arabic (L1) and French (L2). However, addressing non-equivalence in some cases, will pave the way for introducing several methods and procedures to overcome this problem.
\end{abstract}

Keywords: Technical translation, Translation equivalence, non-equivalence, Informal Economy

\section{Introduction}

Nobody has ever said how many ways there are in skinning a cat. Probably, it is the same number of ways when tackling and exploring the world of translation. However, apart from the heated controversy about this latter, there is almost a common belief that the ultimate goal of any translator is to bridge the gap between languages and cultures by establishing an equivalent meaning to the original text or source text (ST) in the Target Text (TT). But this search for equivalence is not an easy task. On the contrary, this mission is fraught with many hurdles ranging from linguistic to paralinguistic obstacles. In fact, each language has its linguistic specificity which does not have necessarily its equivalent in another language.

In order to dig further into the issue of equivalence, the following sections are to lay bare the linguistic hurdles when it comes to translate an economic text from English as a SL, into Arabic and French as TL. The variety of tongues and the resulting language and stylistic differences, coupled with the "technicity" of the text that deals with Informal economy, would offer a paramount opportunity to explore the intrinsic linguistic and technical sides of the realm of specialized translation.

Last but not least, the last section of this paper is to assess the obtained results as well as to raise awareness about the issue of non-equivalence.

\subsection{A tentative definition of translation}

It is commonly agreed that translation is that complex linguistic process to move from an original text or Source Text ( ST) written in a certain Source Language (SL) into another text called Target Text (TT) in a another different language or Target Language (TL).

The linguist Peter Newmark points to translation as "a craft consisting in the attempt to replace a written message or statement in one language by the same and/or statement in another language." (Newmark, 1981: 7)

Following the same train of thought of Newmark, E.A Nida summarizes this complex linguistic situation by saying that "Translating consists in producing in the reception language the closest natural equivalent to the message of the SL, first in meaning and second in style". Nida and Taber (1969: 12)

These two linguists argue that there are two forms of equivalence; The formal and the dynamic equivalence. As far as the formal correspondence is concerned, it 'focuses attention on the message itself, in both form and content', unlike dynamic equivalence which is based upon 'the principle of equivalent effect' (1964:159). In the second edition (1982) of their work, the two theorists provide a more detailed explanation of each type of equivalence. Formal correspondence consists of a TL item which represents the closest equivalent of a SL word or phrase. Nida and Taber make it clear that there are not always formal equivalents between language pairs. They therefore suggest that these formal equivalents should be used wherever possible if the translation aims at achieving formal rather than dynamic equivalence. 
This process of 'retextualizing' from the SL into the TL requires knowledge of the source and target languages and their intrinsic linguistic characteristics as well as knowledge of the topic dealt with, and this assumption dates back to the 13th century, when Roger Bacon wrote that "if a translation is to be true, the translator must know both languages".

The translator's role in relation to a text has been compared to that of an artist, e.g., a musician or actor, who interprets a work of art. Translation, like other arts, inescapably involves choice, and choice implies interpretation. It is no surprise then that we find the English-language novelist Joseph Conrad advising his niece and Polish translator Aniela Zagórska:

Don't trouble to be too scrupulous... I may tell you (in French) that in my opinion "il vaut mieux interpréter que traduire" ["it is better to interpret than to translate"].... Il s'agit donc de trouver les équivalents. Et là, ma chère, je vous prie laissez vous guider plutôt par votre tempérament que par une conscience sévère.... [It is, then, a question of finding the equivalent expressions. And there, my dear, I beg you to let yourself be guided more by your temperament than by a strict conscience....]

However, one might wonder here whether Joseph Conrad would keep the same opinion of being guided by "temperament" in translation rather than "a strict conscience" if we have a technical text, like in our case, to translate?

\subsection{Technical translation}

Needless to mention that when it comes to technical translation, which is the case in this work, the translator's mission becomes harder since there would be no room for mistakes. Mistakes in this field, indeed, may be disastrous.

Certainly, Conrad, if alive, would change his mind and would think of "a strict conscience" when dealing with technical terms.

That is, translation errors on the job may very well lead to disasters. In chemical texts they can cause fatal poisoning or terrible explosion. In legal translation they can unlawfully make a defendant lose a crazily expensive law-suit. In aeronautics they may bring a plane down from the sky on people's heads. The poor performance of an interpreter can spoil the proceedings of a whole international conference.

The issue of this special translation rises from the fact that the texts translated are special and the words used are specific to a particular register; mainly scientific terms. Byrne (2006) deals with the aim of this type of translation, and how getting to this aim is full of difficulties. According to Byrne:

the aim of technical translation is to transmit technical information, this would be just half of the story... and are intended to serve a relatively finite purpose namely to clearly present information to the target language readers...the challenge for technical communicators is to ensure that all of the relevant information is indeed conveyed but...conveyed in such a way that the readers can use the information easily, properly and effectively. (2006:10)

Therefore, technical translation is not easy; it is not just about terminology and it is accurate translation. Byrne further argues that technical translation, just like any other sort of translation, is not reproducing a text but it communicates something for a new audience as the original text did for the original audience.

As a field, technical translation has been recognized, studied, and developed since the 1960s. Stemming from the field of translation studies, the field of technical translation traditionally emphasized much importance on the source language from which text is translated. However, over the years there has been a movement away from this traditional approach to a focus on the purpose of the translation and on the intended audience.

According to Kingscott Geoffrey in his "Studies in Translatology" (2002), this is perhaps because only 5-10\% of items in a technical document are terminology, while the other $90-95 \%$ of the text is language, most likely in a natural style of the source language.

Though technical translation is only one subset of the different types of professional translation, it is the largest subset as far as output is concerned. Currently, more than $90 \%$ of all professionally translated work in the world is done by technical translators, highlighting the importance and significance of the field. . In this context Kingscott argues: "It has been estimated that technical translation accounts for some $90 \%$ of the world's total translation output each year." Kingscott (2002:247). To many, this is unsurprising given the importance attached to the availability of technical information in a variety of languages.

\subsection{Necessity of equivalence in Translation}

As can be easily seen in the above, no matter how translation is defined, the concept of equivalence is inseparable and is implied in one way or the other. In a sense, each of the above definitions is constructed round the basic concept of equivalence, or as Marry Snell-Hornby points out that definitions of translation may be regarded as variations of the concept of equivalence. (Snell-Hornby: 15) The essentiality of the concept of equivalence in any definition of translation demonstrates adequately the necessity of equivalence in translation.

The comparison of texts in different languages inevitably involves a theory of equivalence. Equivalence can be said to be the central issue in translation although its definition, relevance, and applicability within the field of translation theory have caused heated controversy, and many different theories of the concept of equivalence have been elaborated within this field in the past fifty years. As a matter of fact, this issue will be of paramount utility since the translation practice in this thesis involves English as a source language, and Arabic and French as target languages. In the coming sections, this linguistic journey between three languages seems fraught with many hurdles, but full of challenges. The overriding objective in this challenging research and journey is reaching Translation Equivalence. 
The moral here is to try to find a balance between setting a tone that indeed celebrates interesting findings without too many leaps, and reporting limitations without being unnecessarily negative. The mission seems fraught with many puzzles.

Therefore, in this section the aim is twofold; the first purpose is to show some fruitful findings after translating an economic document. Secondly, difficulties and hindrances throughout the translation process are to be emphasized.

\section{Findings}

\subsection{Translation methods used}

No doubt, a good translator must be knowledgeable about the different techniques and theories of translation. These methods are extremely helpful when translating a text, being general or technical. Here are some of the methods used while translating the economic report.

a. Transposition: This is the process where parts of speech change their sequence when they are translated. It is in a sense a shift of word class.

• "Monthly net income" = الاخل الثهري الصافي = "le revenu mensuel net."

Transposition is also called "shift" (Catford). It involves a recategorisation, i.e. a change in the grammar from source language to target language like the position of the adjective in the previous example.

In addition, while English has a preference for nominal sentences, Arabic is reluctant to begin with a noun, preferring verbal sentences like in this example:

- Gathering the economic facts in the shadows of the law requires in-depth

fieldwork= يتطلب جمع البيانات الاقتصادية التي أفلتت من رقابة القانون عملا ميدانيا في العمق

b. Modulation: Modulation (i.e. using a different phrase to convey the same meaning) is used to get closer to what the author intends to say.

See for instance how “in the shadows of the law” in English became "التي أفلت من رقابة القانون " in Arabic.

c. Expansion (étoffement): In many cases I found it necessary to add some words in the target text to reveal the intended meaning of the source text and to obtain the needed translation equivalence (TE) like:

- Too many obstacles to legality= : عديد العراقيل تحول دون الممارسة القانونية للتجارة

Here a paramount attention is given to the meaning. Firstly, I had to decipher or decode the message in the target text. Secondly, I encipher or formulate the target text.

Addition of information for specification purposes is also required "if ambiguity occurs in the receptor language formation and if the fact that greater specificity may be required so as to avoid misleading reference" (Nida, 1964: 227)

d. Borrowing: The writer of the English report has borrowed several words from Arabic like: "ras el mél", "hogra", etc. So my job here is just to bring back the Arabic words in my translation since the writer borrowed them in order to give his text that authentic meaning of the investigation into the extralegal economy of Tunisia. In fact, the borrowing here is not because the target language does not have a lexicalized correspondence or equivalent but it happens to achieve the aim of the text. Otherwise, the writer could say simply and respectively: capital and despise.

A striking noticeable example of borrowing in this translation is when dealing with the words: "slumdogs","Naxalite", "favelas" and "mafias" which are typical names for specific groups in some countries and they do not match equivalents in the TL.

e. Adaptation: One should dig deep into the works of many talented translation experts and linguists to use such a technique. Vinay and Darbelnet ( 1973) call it adaptation, Newmark (1991) label it cultural equivalent. It is about trying to find the nearest equivalent in the target language when there is a problem of equivalence, i.e. in case of nonequivalence. To illustrate, I can mention these examples:

\section{- Formality = إجراء قــانونى}

But when we think about the source text again, we find it essential to add a word in Arabic

which means that this formality is binding. So, the expression in Arabic would be:

\section{التقيد بالإجراءات الرسمية}

- Informality = عدم التقيد بالقانون

Here the opposite is expressed through the prefix « in », so in Arabic it was necessary to add the word "عدم " to mean the absence of formality.

- $\quad$ Extralegality = الاقتصاد الموازي

I found that the word "Extralegality" bears out the meaning of the informal or underground economy. Thus adoption here is a necessary tool to get the equivalent in the target language. So I used the notion of "لاقتصاد" الموازي. But it seems that the adjective "الموازي" is an automatic transfer of the French adjective "parallelle".

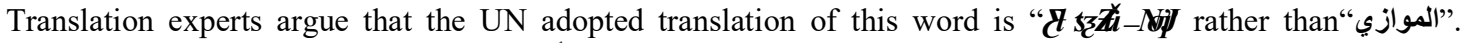

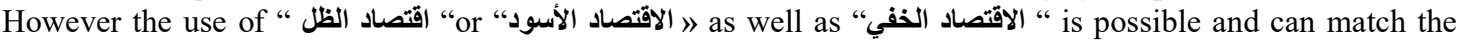
intended meaning and equivalence in the target text.

2.2 The use of context

No doubt, the process of translation is fraught with many linguistic and paralinguistic considerations. In fact it is not enough to just understand the meaning of the words but it is paramountly important to get familiar with the context. 
For example, consider the following sentence, taken out of context: "With a large number of readers and relatively few writers, there is the possibility of writer starvation." Without some sufficient co-text(surrounding sentences), one might think it is talking about human readers and writers, when in fact it is talking about components of a computer software system (IBM, 2008).

Another example I always think of when translating is that one given by Newmark in the introduction of his work A textbook of Translation: When do you translate "Il fait froid" as 'It's cold' and when as 'I'm cold', I'm freezing, I'm so cold', etc.? Surely the answer is "depending on the context"!

\subsection{The use of IT in translation}

It is commonly argued that machine translation can never be as appropriate and "correct" as the human translation. However, we cannot ignore the fact that technology is a sine qua non condition nowadays for the translator as well as the teacher and the students of translation to better perform.

In fact, Internet does not provide us with translation engines on line only, but also it can accompany the translator all over his translation.

We can make use of Internet a lot when consulting invaluable books and articles linked to both translation and the theme of my translation here which is informal economy. Without such an easy and rapid tool, many ideas would not see the light.

It is worth mentioning that some online dictionaries are helpful in case of some difficult technical terms.

\subsection{Handling the problem of common mistakes}

The process of translation is fraught with many hurdles that may hamper an appropriate translation. In this part of the paper, I will come across some cases which present a source of mistakes in the Arabic translation in general and for the Tunisian learners in particular.

a. The false cognates (Also false friends): They are pairs of words in two different languages that look or sound similar but differ significantly in meaning. In fact the influence of French as a second language (L2) in Tunisia seems remarkable when dealing with a translation from English as (L3) into Arabic as (L1) or vice versa. Here I give an example that seems confusing:

The word "credit" in English may lead to the French word "crédit" and consequently to a totally different and inappropriate term in Arabic which is "قرض. However, credit in English does not mean loan only but also, like in this context, it means simply "sum of money in sb's bank

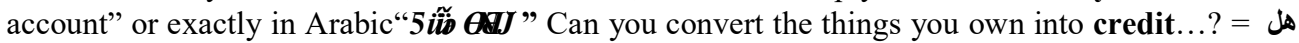
تستطيعون تحويل ما تملكون إلى مال

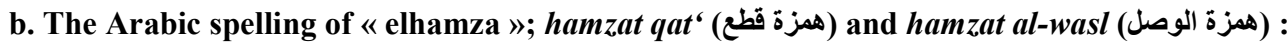

It is not unimportant to shed the light on the difference between these two spelling features. My main focus here is not on the rules of the spelling of "hamza")(هزة) in general, but rather on its spelling when it comes to nouns starting with "hamza". As a matter of fact, I will give some of these nouns that cause a remarkable confusion for Tunisian learners in order to get the rule after:

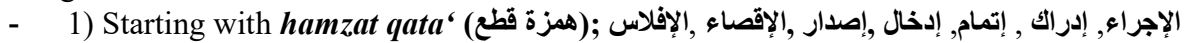

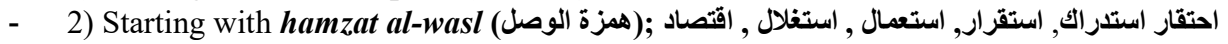

So all the nouns in the first list start with hamzat qata' because the verb of these nouns is four letters, i.e. the

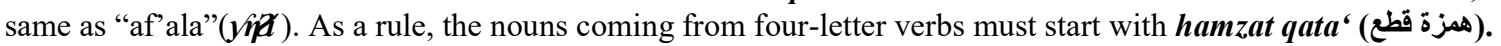

However, the nouns in the second list can never start with hamzat qata', as commonly and wrongly used, but they start with hamzat al-wasl (هزة الوصل) since the verbs these nouns come from are not four letters, i.e. they are not the same as "af'ala"'(yấ).

It goes without saying that my focus on this common mistake is on purpose, because I have noticed this spelling error many times throughout my students translation works, in highly official documents or even in the names of some ministries like وزارة الشؤون الاجتماعية or the well known and the leader in telecommunication services in Tunisia تصالات تونس الاتحاد العام التونسي للشغل In other famous and old institutions like. In the examples, they do not hesitate to start wrongly with hamzat qata' instead of hamzat al-wasl.

\section{c. Unnecessary use of the passive voice in Arabic:}

Another common mistake I have frequently noticed and come across, is the automatic transfer of the passive in English into the same voice in Arabic. However, Arabic, unlike English, tends to use active sentences much more than the passive ones. Here is an example from my translation to illustrate the tendency of Arabic, unlike English and French, to use an active construction;

- The result is that the value of legalization to development is tremendously underestimated $=$ Le و النتيجة أن = résultat...l'importance de la legalization au développement est considérablement sous-estimée العديد لا يقدرون أهمية تقتين الأعمال في النمو

As we can clearly notice, we have moved from a passive form in English"...the value....is underestimated" and French "la valeur...est sous-estimée" into the active form in Arabic: العديد لا يقدرون أهمية تقنين الأعمال.

In brief, one should mind the specific language differences between the source text and target text, to achieve his ultimate goal: Translation Equivalence. 


\section{Limitations}

\subsection{The problem of non-equivalence}

When she tackles problems arising from lack of equivalence at the word level, the Egyptian linguist Mona Baker (1992/2006) asks herself what a translator does when there is no word in the TL which expresses the same meaning as the SL word?

Although she attempts to outline some of the most common types of non-equivalence

which often pose difficulties for the translator and some attested strategies for dealing with

them, Baker admits that: "It is virtually impossible to offer absolute guidelines for dealing

with the various types of non equivalence which exist among languages" (1992/2006: 17).

Nevertheless, a translator needs to be aware of some strategies which may be used to deal with non-equivalence in certain contexts.

Certain suffixes and prefixes, for instance, which convey prepositional and other types of meaning in English often have no direct equivalents in other languages.

To illustrate, I give this example: the word "extra legality" which was used many times by Desotto has not been easy to decipher. After reading the whole document to get the gist of the text, things have become clearer especially that the report is about an investigation into the informal or background economy. As a matter of fact the nearest and the most appropriate equivalent in French was clearly "Economie informelle". But although the Arabic equivalent for this term can be “ الاقتصاد الموازي, translation experts argue that the expression adopted officially by the United Nations is " od ¿

It is most important for translators to understand the contribution that affixes make to the meaning of words and expressions, especially since they are often used creatively in English to coin new words.

\subsection{The technical terms}

Technical translation process is fraught with many hurdles and risks. In fact, the translator has no room for mistakes. For each purely technical term, you cannot find many equivalents like the general words. To illustrate this difficulty, I will give you this example from the translation into Arabic;

When I came across the technical term "creditworthiness » for example, and knowing it means literally " المصداقية في "خلاص الاين", I was about to mistranslate it. In fact, we cannot risk using such an expression without checking in specialized dictionaries or websites.

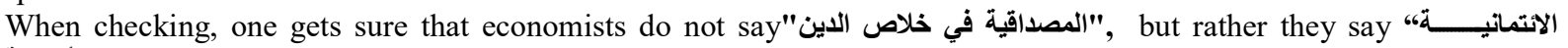
الأهليـ".

In this context of looking for the appropriate equivalent, one cannot forget to mention Vinay and Darbelnet arguing that "the need for creating equivalences arises from the situation, and it is in the situation of the SL text that translators have to look for a solution"(1998). Indeed, they conclude that even if the semantic equivalent of an expression in the SL text is quoted in a dictionary or a glossary, it is not enough, and it does not guarantee a successful translation.

\subsection{The polysemous words}

"Polysemy (or polysemia) is a compound noun for basic feature. The name comes from Greek poly (many) and semy (to do with meaning as in semantics). Polysemy is also called radiation or multiplication. This happens when a word acquires a wider range of meanings" (Quiroge -Clare: 2003). For example: "note' is "a musical tone" or "a short written record". "Not only do different words have different meanings; it is also the case that the same word may have a set of different meanings. This is polysemy; such a word is polysemic." (Palmer, 1976: 100)

For example: flight means: 'passing through the air', 'power of flying', 'air journey', 'unit of air force', and many others. So a polysemic word is a word with different meanings and, therefore, problems rise and ambiguity becomes the first issue whenever these words are used.

One of the puzzling polysemic words I came across throughout the translation of the economic report is "bill'. It can mean "written statement of money owed for goods or services supplied", "written or printed advertisement", "programme of entertainment", "draft of a proposed law to be discussed by a parliament", "a bird's beak", and some other meanings.

The crucial thing for the understanding of a word is context. So, the translation of this word requires an understanding of its context. Therefore, the word "bills" matches "des bons" in French and " سندات "in Arabic because the context of the surrounding words in the sentences bears that meaning; "Issue bills to raise financing" = «Emettre des bons pour augmenter le financement” = " إصدار سندات لزيادة حجم التمويل "

\section{Results}

In this crucial part of the paper, I will try to tackle the issue of equivalence in this economic translation. In fact, the translator's ultimate objective is achieving equivalence; I have used different strategies and techniques to achieve equivalence. However, I might sometimes miss that objective because of many linguistic and paralinguistic factors.

An extremely interesting discussion of the notion of equivalence can be found in Baker (1992) who seems to offer a more detailed list of conditions upon which the concept of equivalence can be defined. She explores the notion of equivalence at different levels, in relation to the translation process, including all different aspects of translation and hence putting together the linguistic and the communicative approach. I will try here to use Baker's typology about equivalence and see its relevance in the economic translation. 
Equivalence that can appear at word level and above word level: equivalence at word level is the first element to be taken into consideration by the translator.

In fact, the equivalence at this level is of paramount importance in general translation, let alone in the technical one, where the translator does not have a vast choice between equivalents. One, in this economic translation for instance, cannot find other equivalents for these terms: Arab Spring = Printemps Arabe = الربيع العربي

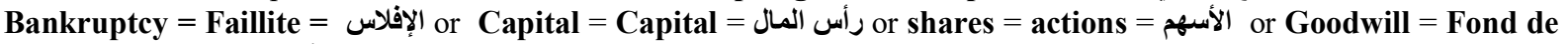
commerce = الأصل التجاري etc.

Therefore, the translator here should know and find the exact equivalent for such technical terms, and any confusion or mistake would blur the whole work.

Grammatical equivalence: Baker notes that grammatical rules may vary across languages and this may pose some problems in terms of finding a direct correspondence in the TL. Amongst these grammatical devices which might cause problems in translation, Baker focuses on number, tense and aspects, voice, person and gender.

To illustrate this type of equivalence, one can point to the use of the active voice in Arabic although the voice is passive in English and French, like:

the value of legalization ... is tremendously underestimated

$=\ldots$...importance de la legalization ... est considérablement sous-estimée

العديد لا يقرون أهمية تقنين الأعمال ....

In the same example, we can obviously notice the gender issue in the French as well as Arabic grammar, unlike English which is a non-gender language. So for the word "importance" the past participle must take the female "ée" at the end.

In addition, the translator cannot reach equivalence unless he cares about the equivalence in tenses which vary across languages.

Textual equivalence: when referring to the equivalence between a SL text and a TL text in terms of information and cohesion.

This type of equivalence has been clearly and necessarily matched in the translation of this document about the informal economy in Tunisia. Otherwise, one cannot speak about a translation that misses the information of the source text or lacks coherence and cohesion in the target text.

We should refer here to the linguist Nida for example, who distinguishes between Formal equivalence which consists of a TL item which represents the closest equivalent of a SL word or phrase and Dynamic equivalence which is defined as a translation principle according to which a translator seeks to translate the meaning of the original in such a way that the TL wording will trigger the same impact on the TC audience as the original wording did upon the ST audience (Nida and Taber, 1982:200). The key point here is that Nida and Baker for instance are in favour of the application of dynamic equivalence, as a more effective translation procedure since the formal correspondence may distort the meaning of the ST.

The principle of the dynamic equivalence can be grasped here in this example of the translation where one should care about the meaning rather than the rank of the words in the source text:

“... in the shadows of the law” = التي أفلت من رقابة القانون " . So the translator should translate the meaning here rather than following the structure of the English sentence word by word.

However, the translation equivalence has also been achieved by following the word rank in the source text, thus in an economic text, like a general one, formal translation can be used to achieve equivalence as in this example: Legalization means creating economic knowledge = La Légalisation signifie la création d'une connaissance économique = إن التقنين يعني خلق معرفة اقتصادية

The translation here has not undergone changes at the level of the structure. In fact we have a Subject + Verb + Object structure in the three languages.

Pragmatic equivalence: when referring to implicatures and strategies of avoidance during the translation process. Implicature is not about what is explicitly said but what is implied.

We all know that technical translation does not mean a translation of texts purely technical. We have technical terms that pragmatics cannot serve in their translation. But a great part of the economic text encompasses ordinary words that the writer can use them beyond their meaning to match his purpose. One should care about what the writer implicitly و نزع الملكية هو اهانة ومس من الكرامة. =wants to say. Hence, I give this example: expropriation is indignity

Another example where I have not hesitated to translate the intention of the writer is when describing how quickly has the move of the revolution from Tunisia to other countries been :

In the English ST, the writer says:

“.... may help to explain why the revolt initiated in Tunisia spread so quickly..."

In the Arabic TT, to convey this meaning of "'so quickly", I have used an image from Arabic that says it all:

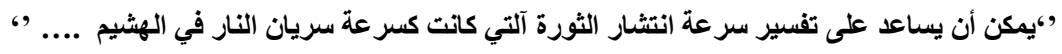

To sum this up, one can assert that no translator ends up with a full satisfaction with his work. In fact, the variety of languages coupled with the socio-cultural differences between people and countries might hamper the mission of the translator. However, the linguistic expertise in both the source and target languages is a sine qua non condition to reach the intended equivalence and the appropriate translation.

It goes without saying that the linguistic practice and analysis in this paper, can serve in showing the different tools used to face the hurdles when translating a technical text. 
However, a deeper comparative study and a more scientific investigation into the complex linguistic realm of Arabic, English and French seem necessary to explore this challenging search of equivalence between the three languages. Neither the scope nor the objective of this paper would allow such a profound study.

\section{Conclusion}

To conclude, we can say that the issue of equivalence can never stop raising heated debates among linguists and translators. Although the findings in this paper have stressed the importance of the different translation methods to decipher the source text and establish the intended equivalence in the target text, this work is still far from unveiling the hidden linguistic specific aspects of each language. In fact English and Arabic have totally different linguistic aspects. Thus, a translator can never dare to reach a total equivalence because of the impossibility of sameness in one language, let alone in two or more languages. This puzzling and perplexing search for equivalence seems more farfetched if the translator lacks some linguistic knowledge in the source or the target language.

In addition, the process of translation is not only based on how much is the translator familiar with the intrinsic linguistic aspects of the language but also it has much to do with the ability to decipher the intention of the writer, i.e. the pragmatic side of the language. Hence, throughout the translation of an economic report, the translator should be aware of the social and cultural background of the writer of the source text. Not less important, he must diagnose the aim of the translation and the audience, or the receiver of the target text.

It goes without saying that the aforementioned hindrances become much more complicated when it comes to the translation of a specialized text with a technical terminology, like in the economic translation in this paper. In this case, the translator has no room for mistakes that will blur the whole meaning since the choice of an equivalent technical term must be precise and appropriate.

Last but not least, the tentative to lay bare the different translation methods to reach equivalence, and overcome some situations of non-equivalence between English, Arabic and French, cannot give a final scientific solution to tackle the issue of translation equivalence.

It is not unimportant, indeed, to remember that translation can never be that mechanical operation. Thus, many linguistic and paralinguistic factors determine this process. Still, the ever problematic and heatedly debated question among theorists: Can translation be taught? cannot be ignored. A positive answer seems a sine qua non condition to reconsider the way translation is taught as well as assessed in Tunisia. As a matter of fact, the issue is so paramount and challenging that it needs further and deeper empirical research.

\section{References}

Atlas Encyclopedic Dictionary (2002). English - Arabic, Atlas Publishing House, Second Edition.

Baker, M. (1992/2006). In Other Words: A Course book on Translation, 2nd edn. London and New York, Routledge.

Baker, M. (1992). In Other Words: A Course book on Translation. London: Sage Publication.

Bassnett, S. (2002). Translation Studies, 3rd rev. edn. London, Routledge.

Bell, R. T. (1993). Translation and Translating: Theory and Practice, London and New York, Longman.

Byrne, J .(2006). Technical Translation: Usability Strategies for Translating Technical Documentation. Dordrecht: Springer.

Catford, J.C. (1965). A Linguistic Theory of Translation, An Essay in Applied Linguistics. London, Oxford University Press.

Christopher, K. (1983). The Translator's Endless Toil", The Polish Review, XXVIII, 2, pp. 84-87.

Collins York English Dictionary' Fourth Edition, Librairie du Liban Publisher by special agreement with Harper Collins Publishers, (n.d).

Darir, H. (2010). Affixation in Arabic: A terminological Perspective on modern Arabic Scientific and Technical Terms". In Academia

De Soto, H. (2005). Le mystère du capital: Pourquoi le capitalisme triomphe en Occident et échoue partout ailleurs.Nouveaux Horizons-ARS, Paris, 2005

(2002). Law and Property Outside the West: A Few New Ideas About Fighting Poverty", NUPI. December 2002, pp. 349-361.

January 2006. (2006). What if you can't prove you had a house?", International Herald Tribune/New York Times, 20

Finch, C. (1969). An Approach to Technical Translation: An Introductory Guide for Scientific Readers. New York: Pergamon Press, 1969.

Institute for Liberty and Democracy. (2009). The ILD's war against exclusion, p. 19.

Kingscott, G. (2002). Studies in Translatology. Perspectives, $\quad$ 10(4): 247255. http://www.informaworld.com/smpp/content $\sim \mathrm{db}=$ all content=a921760804M.

Matthea B. (2013) Property Rights, Rule of Law, and the Spark of the "Arab Spring”, 27 september 
Namit B, ed. (1992). The Oxford Companion to the English Language, pp. 1,051-54

Newmark, P. (1988a). Approaches to Translation, Prentice Hall International.

(1988b). A Textbook of Translation, Prentice Hall International.

Nida, E. A. (1964). Towards a Science of Translating, Leiden: E. J. Brill.

Nida, E.A., and Taber, C. (1969/1982). The Theory and Practice of Translation, Leiden: E. J. Brill.

Palmer, F. (1976). Semantics. Cambridge: Cambridge University Press

Quiroga-Clare, C. (2003). Language ambiguity: a curse and a blessing. Translation Journal, 7(1). http://accurapid.com/journal/23ambiguity.htm

Snell-Hornby, M. (2006) The Turns of Translation Studies: New Paradigms or Shifting Viewpoints?, Philadelphia, John Benjamins,

Thompson, D. (1967). Theophilus Presbyter: Word and Meaning in Technical Translation. Medieval Academy of America, 42(2), 313-339. http://www.jstor.org/stable/2854679.

Thomson A.J., and Martinet, A.V (1986). A practical English Grammar. Second Edition, Oxford University Press.

Vinay, J.-P., and Darbelnet J. (1977). Stylistique comparée du français et de l'anglais, Paris, Didier.

(1995). Comparative Stylistics of French and English: A Methodology for Translation, Translated and

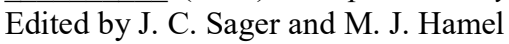

